Reflection

\title{
Digesting Losses
}

\author{
Marjorie Jacobs ${ }^{1}$ \\ ${ }^{1}$ Boston University Center for Psychiatric Rehabilitation, Boston, United States of America
}

\begin{abstract}
Psychiatric rehabilitation aims to promote health recovery from significant losses that have derailed the lives of adults and young adults in order for them to actively participate in rebuilding and recreating themselves. Most of the mind-body, rehabilitation interventions I design and teach utilize music to boost mood and motivation, meditation (sometimes combined with nature sounds) to elicit the relaxation response, and a variety of mindfulness practices to cultivate attention and awareness, acceptance, compassion, an expanded perspective, accurate perceptions, and optimism.

The poem Digesting Losses was inspired primarily by my 14-week, mindful eating intervention entitled Eat, Drink \& Be Merry the Mindful. The participants were adults with a comorbidity of mental illness (trauma- and stressor related disorders, anxiety, depression, eating disorders,) and a physical health condition(s) (obesity, diabetes, gastroesophageal reflux disease, and/or metabolic syndrome). I wrote Digesting Losses in the first-person plural narrative to express the experiences of my students. The poem is about their engaging in walking meditation, singing, listening to upbeat music and later calming sounds (a gong and recorded ocean breakers), and mindful eating to help process and transform significant losses. The poem alludes to the connection between the gut microbiome and health.
\end{abstract}

Keywords: recovery, trauma- and stressor-related disorders, depression, music/sound therapy, mindful eating .

multilingual abstract $\mid$ mmd.iammonline.com

\section{Digesting Losses}

We've swallowed losses

some meandered through us

without a trace the next day.

But most wrenched our gut

backed up

burning our esophagus

regurgitating acidic thoughts

cycling between worries and should haves

keeping us awake at night.

So, mornings we're ingesting the tonic:

bright melodies with bouncy beats

driving us to swing hips and sing

and walking meditation mellowing

our minds savoring acceptance.

PRODUCTION NOTES: Address correspondence to:

Marjorie Jacobs | Address: BU Center for Psychiatric Rehabilitation, 940 Commonwealth Ave. West, Boston, MA 02215, 6173533562 | E-mail: mljacobs@bu.edu | COI statement: The authors declared that no financial support was given for the writing of this article. The authors have no conflict of interest to declare.
Lunchtime in the classroom

we're preparing for mindful eating

listening to sounds of surf

swelling and breaking

attuning our breath to the waves

noticing hunger undulating, dissipating...

rippling calm and content...

when the gong calls us to eat

and we open our eyes.

In silence we observe

our plates of salad greens

crunchy carrots and red quinoa

and smell the pomegranate vinaigrette

joining our palms for this offering.

After singing gratitude

we are chewing slowly

putting utensils down between bites

focusing on smell and taste

saliva breaking everything down

small pieces smoothed, satiated

by the sweet understanding -

in time everything changes -

the digestion of letting go. 
Biographical Statement: Marjorie Jacobs (MA in Social Change with a CAGS in Integrative Holistic Health Studies) is a psychiatric rehabilitation clinician at the Boston University Center for Psychiatric Rehabilitation where she designs and teaches promising group interventions for adults diagnosed with a serious mental illness based on the applications of mindfulness practice (meditation, cognitive reframing, music listening, singing, dancing, and poetry), positive psychology, and neuroscience with the goals of developing stress resilience and facilitating mental health recovery.

https://cpr.bu.edu/about/directory/marjorie-jacobs 